\title{
Комплексная мульти- и гиперспектральная обработка изображений видимого и ИК диапазонов в задачах обнаружения и классификации объектов на неоднородном фоне
}

\author{
О.И. Потатуркин, С.М. Борзов \\ Институт автоматики и электрометрии СО РАН, Новосибирск, \\ 630090, Акад. Коптюга, 1 \\ тел:+7 (383) 330-4020, факс:+7 (383) 330-8878, эл. nочта: potaturkin@iae.nsk.su
}

DOI 10.34077/RCSP2019-90

Предложен метод комплексной классификации мультиспектральных изображений высокого разрешения. Показано, что для природных и антропогенных зон предъявляются различные требования к параметрам пространственной обработки картосхем, полученных на этапе спектральной классификации. Поэтому с помощью преобразования Харриса формируется маска и выполняется локально-адаптивное сглаживание с помощью процедуры выбора наиболее часто встречающегося класса в скользящем окне разного масштаба. В результате отсутствует излишняя детализация изображений на естественных ландшафтах и обеспечивается необходимая точность классификации на антропогенных территориях.

Разработан метод обнаружения слаборазличимых пространственных изменений, вызванных антропогенным воздействием. Он основан на предварительной спектральной фильтрации с последующим попиксельным формированием разностных кадров и их анализе за счет оценки согласованности изменения во времени одинаковых по яркости пикселей изображений с помощью диаграммы прямого и обратного разброса. Эффективность предложенных методов продемонстрирована на реальных данных дистанционного зондирования Земли.

Установлено, что для эффективной обработки гиперспектральных (ГС) изображений природных и антропогенных территорий недостаточно методов, основанных на сравнении с эталонными спектрами, а необходимо также учитывать распределение данных в пространстве признаков. При обработке тестовых изображений природной зоны и городской застройки показано, что сокращение количества спектральных признаков методом главных компонент (до 15-20 для природной зоны и 510 для городской застройки) позволяет уменьшить трудоемкость обработки на два порядка, без существенного снижения эффективности классификации.

Исследована эффективность методов спектрально-пространственной классификации ГС данных, основанных на предварительном медианном сглаживании обрабатываемых изображений и на постобработке картосхем попиксельной спектральной классификации путем выбора доминирующего класса в локальных окрестностях (или сегментах). Показано, что учет близкорасположенных пикселей позволяет повысить точность классификации ГС изображений. Так доля верно классифицированных пикселей с использованием только спектральных признаков составила для изображения природной зоны - 79.7\%, а использование пространственных признаков позволило ее увеличить до 92-93\%.

Выявлены особенности, позволяющие осуществлять классификацию типов поверхности в поле наблюдения, и в частности выделение антропогенных объектов на естественном фоне. Показано, что для их эффективного обнаружения перспективна совместная обработка спектральных и пространственных признаков с последующим синтезом высокоинформативных изображений.

Рассмотрена возможность разработки и исследования методов и технических решений для повышения эффективности оптико-электронных средств наблюдения и разведки на основе комплексной обработки в реальном времени узкополосных (квазимонохроматических) изображений с многоэлементных фотоприемных устройств видимого, ближнего и коротковолнового ИК диапазонов. 